\title{
SEVEN YEARS OF TANDEM-X: VOLUME LOSS OF GROSSER ALETSCHGLETSCHER, SWITZERLAND
}

\author{
Silvan Leinss ${ }^{(1)}$, Irena Hajnsek $^{(1,2)}$
}

(1) ETH Zurich, 8093 Zurich, Switzerland

(2) Microwave and Radar Institute, German Aerospace Center (DLR), 82234 Wessling, Germany

\begin{abstract}
Grosser Aletschgletscher, the largest glacier in the European Alps, contains $20 \%$ of the entire Swiss ice mass. However, mass balance simulations based on current climate models predict $90 \%$ mass loss by 2100 . The glacier is a super-testsite for the TanDEM-X satellite mission and data series starting from 2011 are available. In this study we analyzed almost 100 digital elevation models computed from bistatic radar interferograms and compare the derived height loss with model predictions. Additionally, we used patch-based offset tracking to determine a new velocity map of the complete glacier. The results show that the current height loss of 3.3 meters per year is close to that mass balance simulation which uses the ensemble median of common European climate models which predict, relative to 1999 , a warming of $4.3^{\circ} \mathrm{C}$ by 2100 .
\end{abstract}

Index Terms - Aletsch Glacier, radar interferometry, mass balance, DEM generation, offset tracking, ice velocity.

\section{INTRODUCTION}

Glaciers provides a major source of freshwater for alpine countries as well as water for hydropower generation. Therefore, predictions about future glacier evolution is crucial for water resource management [1]. Grosser Aletschgletscher, the largest glacier in Switzerland, is more than $22 \mathrm{~km}$ long, covers over $80 \mathrm{~km}^{2}$ [2], is up to $800 \mathrm{~m}$ thick, and its volume of $15 \mathrm{~km}^{3}$ contains $20 \%$ of the entire Swiss ice mass [3]. Similar to all glacier in the European Alps, Grosser Aletschgletscher has shown a strong retreat and retreated by almost $3 \mathrm{~km}$ since 1880 [4] and almost 400 meters within the last ten years [5]. To estimate the future evolution of the glacier, a study by Jouvet et al. published in 2011 uses several possible climate scenarios from the ENSAMBLES project [6] to model the future evolution of Grosser Aletschgletscher [7]. Depending on the chosen scenario, the models predict a retreat of $15-20 \mathrm{~km}$ and a volume loss of $76 \%$ to almost $100 \%$.

In this study, we analyze almost 100 digital elevation models (DEMs) generated by processing single pass interferometric SAR acquisitions from the TanDEM-X satellite mission [8]. Additionally, a velocity map covering the entire Glacier area is generated from the SAR backscatter data.

\section{DATASET}

The dataset contains almost 100 bistatic, dual-pol TanDEM$\mathrm{X}$ acquisitions acquired over the Aletsch region of the Swiss Alps (46.50 N, 8.03 E). The interferometric, effective perpendicular baselines, determining the height sensitivity, are generally small (between 0 and $150 \mathrm{~m}$ ) but larger baselines (up to $1040 \mathrm{~m}$ ) result from the "large baseline acquisition phase" in spring 2015. The alpine topography of the region contains a large elevation range ( $600 \mathrm{~m}$ to more than $4000 \mathrm{~m}$ a.s.1.) which results in considerable occurrence of layover which complicated the interferometric processing. The processing was simplified by subtracting a simulated interferogram based on a reference DEM before phase unwrapping. The highprecision elevation model "swissALTI ${ }^{3 \mathrm{D}}$ " provided by SwissTopo $^{1}$ was used as a reference. The swissALTI ${ }^{3 \mathrm{D}}$ is updated at least every six years with lidar data and optical stereocorrelation data. The vertical precision is $0.5 \mathrm{~m}$ below $2000 \mathrm{~m}$ and $1-3 \mathrm{~m}$ above. The swissALTI ${ }^{3 \mathrm{D}}$ was also used for orthorectification of the backscatter data for offset tracking.

\section{METHOD}

The entire processing was done with an in-house (ETH Zürich) developed software for coregistration, InSAR phase simulation, common band filtering, Goldstein filtering [9], and orthorectification of TerraSAR-X and Tan-DEM-X acquisitions as well as for offset tracking. The entire software is written in IDL except for phase unwrapping where the external software SNAPHU [10] was used.

\subsection{DEM generation}

All single-look complex data (SLCs) were coregistered to a common master. For each acquisition date an differential interferogram was formed relative to a simulated reference interferogram based on the swissALTI ${ }^{3 \mathrm{D}}$. The residual phase difference was converted to height difference. The height difference was corrected for possible linear phase ramps by calibrating the height at permanent scatterers distributed over the

\footnotetext{
${ }^{1}$ Source: Swiss Federal Office of Topography
} 
entire scene. The calibrated height differences were orthorectified and finally added back to the reference DEM. The result is a stack of elevation models in geographic coordinates. The following paragraphs describe the processing step-by-step.

Different spatial resolutions of the seven years of TanDEM$\mathrm{X}$ data were coregistered and resampled to the master resolution. Coregistration was verified by interferograms between consecutive acquisitions. The resulting repeat-pass coherence was used later for permanent scatterer detection.

For historical reasons, the TanDEM-X data over Aletschgletscher are available in two polarizations ( $\mathrm{HH}$ and VV). To benefit from both polarizations, the complex coherence was calculated for both polarizations separately and then averaged. Despite the fact that the $\mathrm{HH}$ and VV polarization are not completely statistically independent (the magnitude of the HH-VV coherence ranges between 0.5 and 0.7 [11]), averaging helped for noise-reduction of the interferograms. For the coherence, a relatively large spatial window of $11 \times 11 \mathrm{px}$ (full width of half maximum of a 2D Gaussian smoothing kernel) was chosen to reduce phase noise in acquisitions with small baselines. Acquisitions with effective perpendicular baselines less than 10 meters were excluded.

To account for the significant wave number shift [12] in large baseline acquisitions a fringe-adaptive common range filter based on patchwise processing of the SLC pairs was implemented and applied before coherence calculation.

The complex coherence was calculated for flattened interferograms, i.e. the topographic phase was removed before interferogram formation. To ensure that the simulated interferograms based on the swissALTI ${ }^{3 \mathrm{D}}$ match the measured interferogram, both interferograms were coregistered with each other. Interferogram coregistration was done by minimizing the residual phase differences which remained after subtraction of the simulated interferogram from the measured interferogram. The required pixel-shift was converted into lat-lon coordinates and the reference DEM was shifted to minimize the residual phase difference. The required shift was minimal and corresponds to a spatial translation of about $10 \mathrm{~m}$. For large baseline interferograms the Goldstein phase filter [9] has been applied on the interferometric coherence.

The residual phase after topography removal contains not only height differences due to ice loss but also systematic phase ramp in range of a several degrees per $10 \mathrm{~km}$. The phase ramp originates mainly from orbit uncertainties [13]. The phase ramp were removed in a first step by fitting and subtraction of a linear plane to the residual phase. This results in an almost constant, but unknown relative height difference with respect to the reference DEM. The phase ramp can also be slightly biased by regions with strong ice loss. The bias is later corrected by permanent scatterers. The ramp-corrected phase difference was converted into height difference by multiplication with the spatially varying vertical wave number $\kappa_{z}$ which was calculated for each point of the reference DEM.

The resulting height difference was calibrated by perman-
Table 1. Deviation of mean annual air temperature $\Delta T_{\gamma}$, summer (Jun - Aug) temperature $\Delta T_{\mathrm{S}}$, and annual precipitation $\Delta P$, by 2100, from the period $1980-2009$ according to [7]. $\Delta H_{50}$ is the simulated height chance rate south of Konkordiaplatz until 2050.

\begin{tabular}{l|cccc} 
scenario & $\Delta T_{\gamma}\left({ }^{\circ} \mathrm{C}\right)$ & $\Delta T_{\mathrm{S}}\left({ }^{\circ} \mathrm{C}\right)$ & $\Delta \mathrm{P}(\%)$ & $\Delta H_{50}(\mathrm{~m} / \mathrm{a})$ \\
\hline ENSmax & +4.8 & +7.7 & -10 & 5.4 \\
ENSmed & +4.3 & +5.5 & +1 & 3.8 \\
ENSmin & +2.9 & +3.7 & -4 & 2.4 \\
\hline
\end{tabular}

ent scatterers. The location of permanent scatterers were extracted from the averaged multi-pass coherences formed by consecutive acquisitions of the entire stack of coregistered SLCs. Ice and snow covered regions showed an almost zero coherence whereas low vegetation and snow free rocks had a coherence of about 0.5 . Points with highest coherence values are almost completely man made structures like buildings. For selection of spatially distributed permanent scatterers, the scene was divided into blocks of $200 \times 200$ pixels. For each block the pixels with the highest coherence were selected, if the coherence was higher than a threshold of 0.7 to 0.9 . Permanent scatterers for which the height difference exceeded a threshold of $\pm 10 \mathrm{~m}$ were rejected.

The calibrated height difference was orthorectified and added to the reference DEM. The resulting time series of elevation models allows for observation of spatially and temporal changes of the ice thickness of glaciers.

\subsection{Velocity maps}

Velocity estimation is based on patch-wise offset tracking by cross-correlation of the intensity image in $\mathrm{dB}$. For each date one intensity image was obtained by averaging the backscatter intensity from the corresponding four SLC images (TSX and TDX in $\mathrm{HH}$ and VV polarization). The averaged intensity was orthorectified to a resolution of $2 \times 2 \mathrm{~m}$ using the swissALTI ${ }^{3 \mathrm{D}}$ to avoid velocity errors resulting from a spatially varying ground-range resolution on steep slopes.

Offset tracking was performed for all consecutive image pairs with a patch size of $80 \times 80$ pixels corresponding to about $200 \times 200 \mathrm{~m}$. The peak position of the $2 \mathrm{D}$ crosscorrelation function was determined with sub-pixel accuracy and converted to velocity. The quality of the cross-correlation function follows from a combination of several factors but is mainly determined by the height of the correlation peak above the noise floor. The stack of resulting velocity maps provided the basis for further analysis of the velocity. The median of the velocity was calculated but also seasonal variations between winter and summer velocities were analyzed.

\section{RESULTS}

The height difference relative to the swissALTI ${ }^{3 \mathrm{D}}$ (2009) is shown in Fig. 1 for the entire region of Aletschgletscher for 


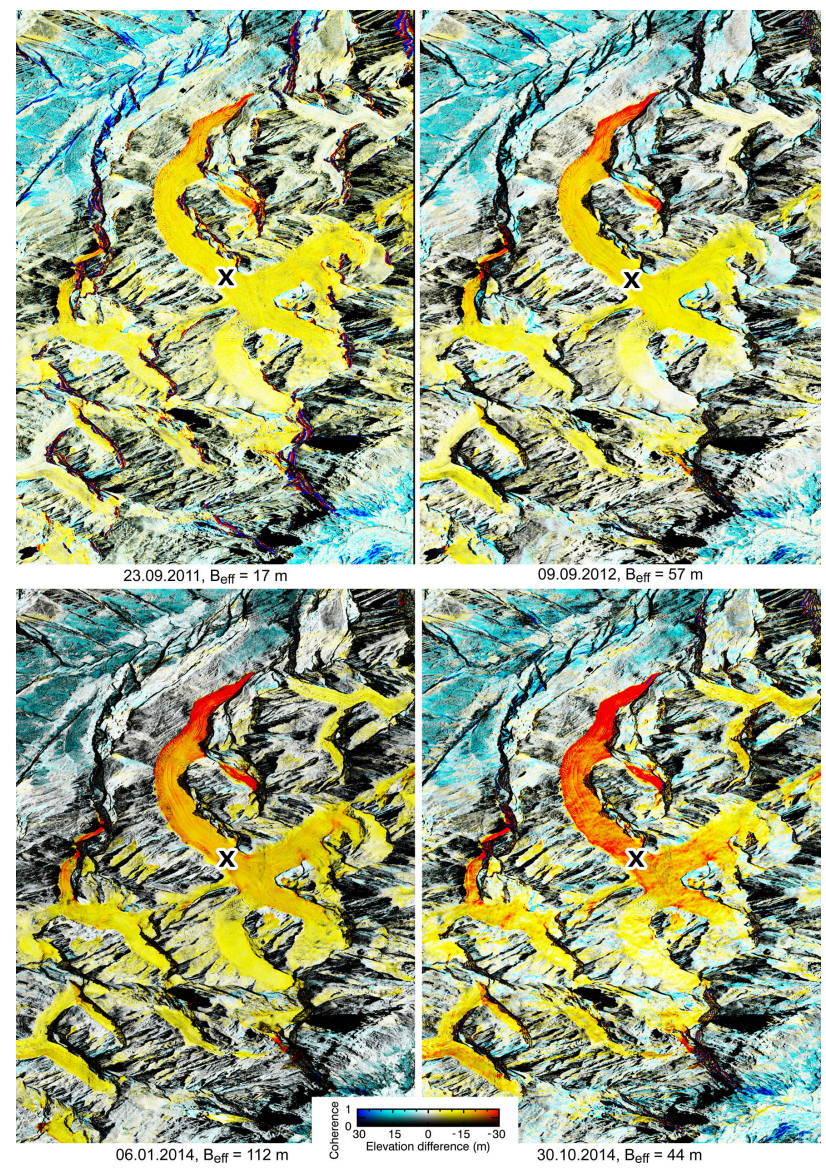

Fig. 1. Height difference between the swissALTI ${ }^{3 \mathrm{D}}$ and TanDEM-X data from 2011 until 2014. An ice loss of 3 - $5 \mathrm{~m} / \mathrm{a}$ is visible by the increasingly yellow to red colors. $B_{\text {eff }}$ is the effective baseline of the TanDEM-X formation. Forests heights of $15-20 \mathrm{~m}$ are shown in light blue.

four consecutive years (Sept. 2011 - Oct. 2014). Height differences are color-coded ranging from yellow $(-10 \mathrm{~m})$ to red $(-30 \mathrm{~m})$ and show an approximate ice loss of $2-6 \mathrm{~m} / \mathrm{a}$. Forest heights of about $15 \mathrm{~m}$ appear in blue because the swissALTI ${ }^{3 \mathrm{D}}$ defines the vegetation-free surface elevation. Shadow and overlay with strong coherence loss appear dark.

The large number of processed TanDEM-X acquisitions made it possible to obtain time series of ice elevation loss. For visualization, an area of $700 \times 700 \mathrm{~m}$ was selected $1 \mathrm{~km}$ south of Konkordiaplatz on an altitude of $2700 \mathrm{~m}$ ("x" in Fig. 1) and the mean height change was computed. Additionally, the height difference standard deviation was determined. The standard deviation is determined by spatial variability of penetration depth as well as by phase noise which causes an increased height error for short baselines. For acquisitions with baseline larger than $1000 \mathrm{~m}$ (spring 2015) one ambiguity height corresponding to about $5 \mathrm{~m}$ was added to the height error to account for possible phase wrapping errors.

The hight difference time series in Fig. 2 (upper panel)

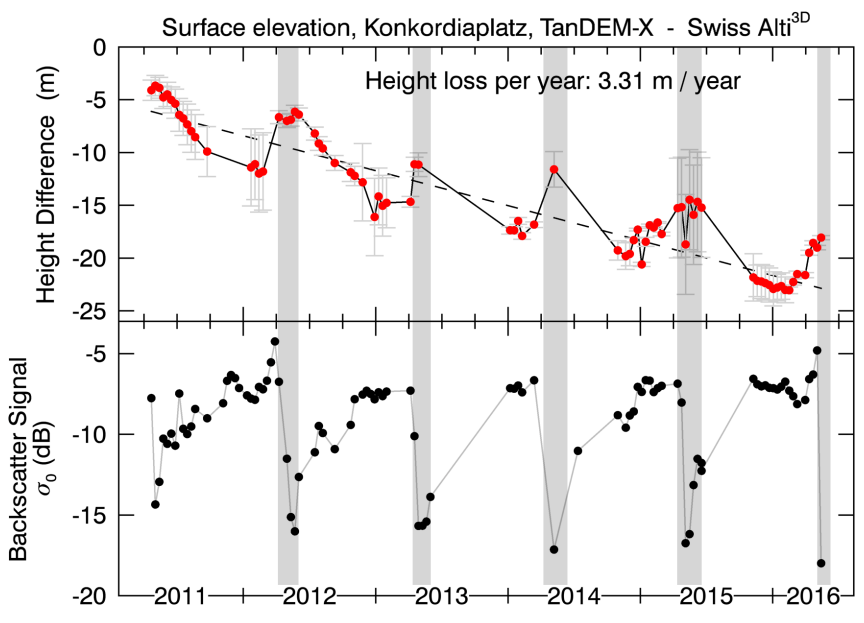

Fig. 2. Height difference between the swissALTI ${ }^{3 \mathrm{D}}$ and TanDEM-X data for an area one km south of Konkordiaplatz ("x" in Fig. 1). The backscatter signal in the lower panel shows distinct dips during snow melt. It must be pointed out that the height seems to increase already just before the backscatter signal declines.

shows an observed elevation loss of almost $20 \mathrm{~m}$ within six years for the selected area. The dashed line is a linear fit to the data and shows an average height loss of $3.3 \mathrm{~m} / \mathrm{a}$. Similar values of $-2.5 \pm 0.2 \mathrm{~m}$ were determined from several DEMs and ICESat data for the period 2003 - 2009 by [14]. During this period annual mean temperature above $1000 \mathrm{~m}$ was $0.5^{\circ} \mathrm{C}$ lower compared to our period from 2011 - 2016 [15]. The comparison to the model predictions (Tab. 1) shows that our measurements agree closely with the ensamble median of climate models "ENSmed" which predicts a height loss of $-3.8 \mathrm{~m} / \mathrm{a}$ and a warming of $4.3^{\circ} \mathrm{C}$ by 2100 .

Fig. 2 shows also a seasonal height variability with a strong height loss during summer. Nevertheless, despite snow fall, the height seems even to continue to decrease in early winter, very likely due to increased penetration into dry snow. This is supported by the abrupt increase of the interferometric phase center in spring (gray shading in Fig. 2) which results from the much smaller microwave penetration depth into wet snow compared to the dry winter snow. Wet snow can easily be identified from the radar backscatter intensity (lower panel of Fig. 2). The strong decline of the backscatter intensity each year in spring indicates the transition from dry to wet snow at the onset of the snow melt season. Importantly, shortly before(!) the decline of the backscatter signal, an apparent height increase of $2-4 \mathrm{~m}$ can be recognized in Fig. 2. From this observation we conclude that the radar penetration is already significantly reduced before the snow shows the distinct decline of the backscatter signal. The abrupt increase of the interferometric phase center is also a measure for the penetration depth of X-band microwaves into dry snow. We observed an average penetration of about $4 \mathrm{~m}$ but for deep 


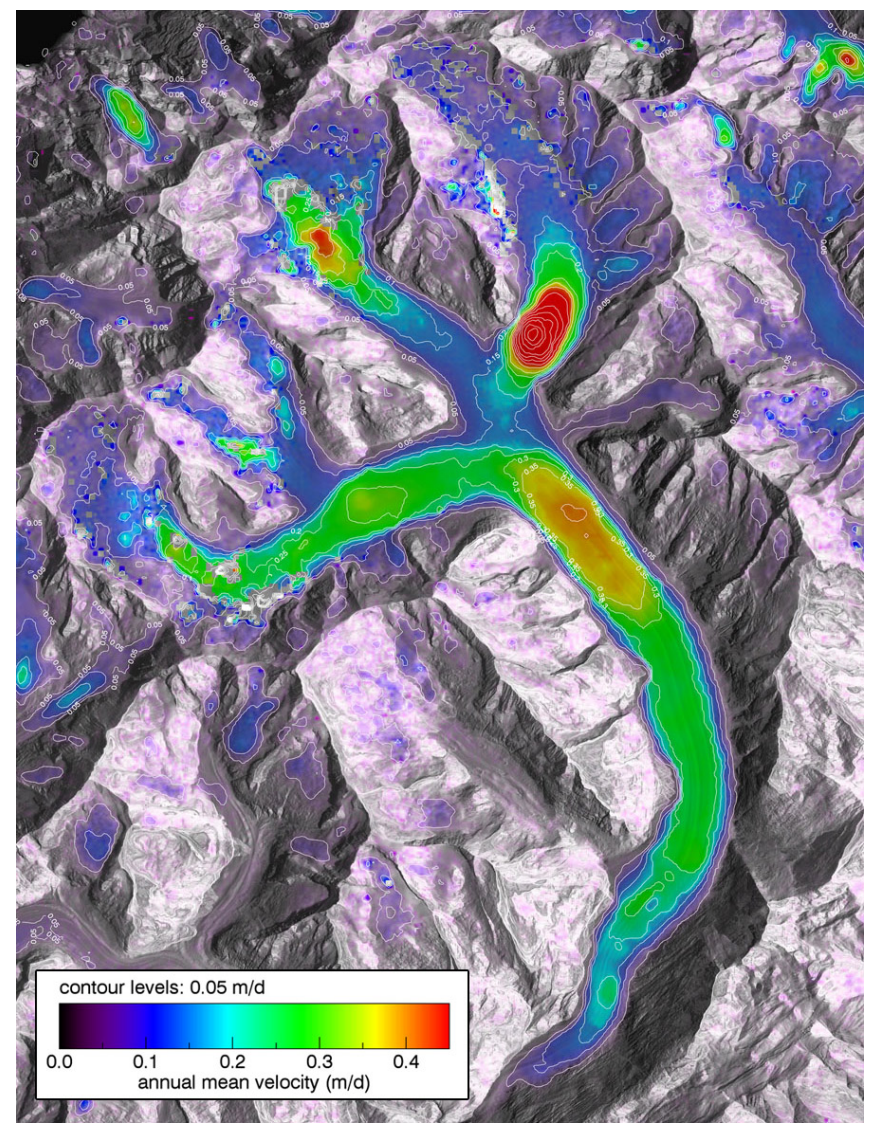

Fig. 3. Velocity map of Grosser Aletschgletscher

firn above $4000 \mathrm{~m}$ we observed penetration up to $8 \mathrm{~m}$.

Finally, Fig. 3 shows the median velocity of Grosser Aletschgletscher for the period 20011 - 2016. The velocity is shown in color ontop of the orthorectified radar backscatter intensity. The velocity map reveals a strong ice flux from the most western arm. Orange and red are higher velocities which occur for steeper terrain. Seasonal velocity variations of up to $50 \%$ (not shown) were found for the tongue.

\section{REFERENCES}

[1] Matthias Huss and Regine Hock, "Global-scale hydrological response to future glacier mass loss," Nature Climate Change, vol. 8, no. 2, pp. 135-140, 2018.

[2] A. Bauder, M. Funk, and M. Huss, "Ice-volume changes of selected glaciers in the swiss alps since the end of the 19th century," Annals of Glaciology, vol. 46, no. 1, pp. 145-149, 2007.

[3] D. Farinotti, M. Huss, A. Bauder, and M. Funk, "An estimate of the glacier ice volume in the Swiss Alps," Global and Planetary Change, vol. 68, no. 3, pp. 225 231, 2009.
[4] VAW-ETH. Zurich, "Glaciological reports. 1881-2015. the swiss glaciers, 1889-2014/15.," Yearbooks of the Cryospheric Commission of the Swiss Academy of Sciences (SCNAT) 1-245, Published since 1964.

[5] VAW/ETHZ and EKK/SCNAT, "Swiss glacier monitoring network," 2016. http://swiss-glaciers.glaciology. ethz.ch

[6] P. Van der Linden and J.F.B. Mitchell, "Ensembles: climate change and its impacts: summary of research and results from the ensembles project.," Met Office Hadley Centre, Exeter, UK, 2009. http://ensembles-eu. metoffice.com/docs/Ensembles_final_report_Nov09.pdf

[7] G. Jouvet, M. Huss, M. Funk, and H. Blatter, "Modelling the retreat of Grosser Aletschgletscher, Switzerland, in a changing climate," Journal of Glaciology, vol. 57, no. 206, pp. 1033-1045, 2011.

[8] G. Krieger, M. Zink, M. Bachmann, et al., "TanDEM-X: A radar interferometer with two formation-flying satellites," Acta Astronautica, vol. 89, pp. 83 - 98, 2013.

[9] R. M. Goldstein and C. L. Werner, "Radar interferogram filtering for geophysical applications," Geophysical Research Letters, vol. 25, no. 21, pp. 4035-4038, 1998.

[10] C. W. Chen and H. A. Zebker, "Snaphu: Statisticalcost, network-flow algorithm for phase unwrapping (ver. 1.4.2)," 2003.

[11] S. Leinss, G. Parrella, and I. Hajnsek, "Snow Height Determination by Polarimetric Phase Differences in XBand SAR Data," IEEE Journal of Selected Topics in Applied Earth Observations and Remote Sensing, vol. 7, no. 9, pp. 3794-3810, 2014.

[12] F. Gatelli, A.M. Guamieri, F. Parizzi, et al., "The wavenumber shift in SAR interferometry," IEEE Transactions on Geoscience and Remote Sensing, vol. 32, no. 4, pp. $855-865,1994$.

[13] G. Krieger, H. Fiedler, M. Zink, et al., "TanDEM-X: A satellite formation for high-resolution SAR interferometry," IEEE Transactions on Geoscience and Remote Sensing, vol. 45, no. 11, pp. 3317-3341, 2007.

[14] J. Kropáček, N. Neckel, and A. Bauder, "Estimation of volume changes of mountain glaciers from ICESat data: an example from the Aletsch Glacier, Swiss Alps," The Cryosphere Discussions, vol. 7, no. 4, pp. 3261-3291, 2013.

[15] M. Begert and C. Frei, "Area-mean temperatures of Switzerland" 2018. http://www.meteoschweiz. admin.ch/product/input/climate-data/swissmean/10. 18751-Climate-Timeseries-CHTM-1.0-north.high.txt 